ON THE ALLEGED DANGERS OF INTRA-UTERINE INJECTIONS OF PERCHLORIDE OF IRON IN CASES OF POST PARTUM HÆMORRHAGE.*

BY FREDERICK POLLARD, M.D.Lond., Senior Assistant-Physician to the Liverpool Infirmary for Children; formeriy Medical Registrar to St. Thomas's Hospital.

[Conciuded from page 62i of last number.]

I HAVE now mentioned every case where death has followed the injection of solutions of perchloride of iron into the uterus for primary post partzım hæmorrhage, and which has been published, or even casually alluded to, in the medical journals or at the obstetrical societies of Great Britain and Ireland in the course of the last ten or twelve years cluring which this method of treatment has been extensively practised. They may not be all the cases which have occurred, but at all events they afford a sufficient basis for an examination of the questions which I commenced this paper by propounding. I shall therefore proceed to analyse and classify them.

To facilitate reference, I will first tabulate them in the order in which I have reported them, mentioning the author's name, and the way in which they proved fatal.

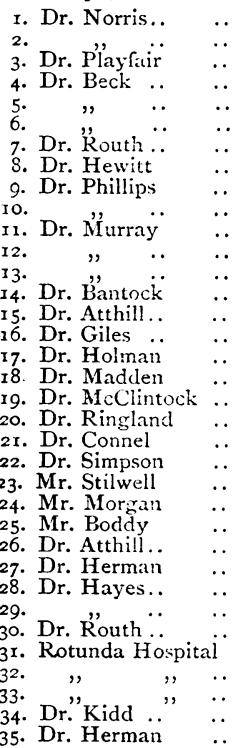

Exhaustion of labour. Placenta prævia.

Recurrent hæmorrhage. Convulsions.

Puerperal fever.

nnconnected with the inje
xhaustion of labour.

Pain and shock.

Puerperal fever.

Peritonitis, pneumonia, etc.

Exhaustion. Fibroids.

Metritis, etc.

Continuance of hæmorrhage.

Metritis, etc.

Recurrent hæmorrhage.

Exhaustion. Injection used too late.

Collapse. No details given.

Recurrent hæmorrhage.

Shock. Sudden death.

Exhaustion (case of transfusion).

Recurrent hæmorrhage.

Continuance of hamorrhage
Exhaustion of labour.

Recurrent hamorringe.

Mania.

Mania.

Ante partum hemorrhage.

Unastion. Convulsions; thrombosis.

No details given.

These cases may be easily arranged into several groups. Firstly, there are eight in which the operation was unsuccessful, the hæmorrhage either continuing or recurring. In each of the two in which it continued (19 and 28), the author explains that the operation was not properly performed. In one instance (34), the author simply says the injection failed, and gives no details. In two cases (2I and 30 ), the patient was already so prostrate that a very slight recurrence of hæemorrhage was sufficient to extinguish life. While in three cases $(3,24$, and 27), the perchloride was applied twice or more, but failed to permanently arrest the hæmorrhage. In a case of this kind, I believe the best chance would be afforded, not by repeating the injection, but by swabbing the interior of the uterus with the undiluted strong solution of the perchloride.

Secondly, there are eleven cases (I, 2, I0, II I I2, I3, I7, 22, 26, 29, 32) in which the reporters state that the perchloride arrested the hremorrhage, but that the patient was too far gone to rally, and died from exhaustion of the labour and the hæmorrhage, in spite of the injection. In several of them, the reporters express their regret that the operation was deferred until too late. In this group, we may probably include Case 9, about which the late Dr. Phillips merely stated that death was quite unconnected with the injection.

In one case (3I), mania set in on the fifth day, and proved fatal on the ninth.

There is one case (23) which it is impossible to classify, owing to the absence of details. It is simply stated that the patient died of collapse after labour and the injection of perchloride. Seeing that the patient

* Read before the Liverpool Medical Institution, March 1880 . was forty-three years old, that it was her first child, and that she had severe post partum hæmorrhage, it is scarcely to be wondered at that she did not survive; but what the immediate cause of death was, or whether the iron had anything to do with it, it is impossible to say.*

There now remain fourteen cases in which there may appear to be some primá facie grounds for connecting the fatal result with the use of the iron. They fall into three groups.

In one case (14), the only one of its kind, the operation was followed by severe pain, and death followed seven or eight hours afterwards. In this instance, the injection apparently caused the pain; and the pain, occurring in a patient already exhausted by severe hæmorrhage, was enough to turn the scale against her. In what way the injection produced the pain, whether by a little of the fluid passing along the Fallopian tubes into the peritoneum or not, is uncertain.

In three cases $(25,33$, and 35$)$, sudden collapse and death occurred at the time of the operation. The first of these (Mr. Boddy's) has already been sufficiently commented on, and can hardly be held to weigh against this method of treatment when carried out with proper precautions.

In the third also, the reporter (Dr. Herman) himself suggests that the cause of the fatal result was want of proper room for the return of the injected fluid.

As regards the Rotunda Hospital case (33), it is unnecessary to add anything to what Dr. Atthill has remarked, viz., that the injection was postponed too long, until, in fact, the patient was at the point of death. The fact mentioned by the reporter, that after death "there was general thrombosis throughout the entire venous system", can scarcely have been due to the iron, since it could not have been produced in the moment or two which appear to have elapsed between the injection and death. It seems more reasonable to suppose that it was a post mortem occurrence.

Lastly, we have ten cases, including the three described by Dr. Beck, in which symptoms of metritis, peritonitis, pyæmia, or septicæmia appeared some days after labour, and terminated fatally. It is a most important question whether these cases can be fairly attributed to the use of the iron injection.

Now, in the first place I would remark that these ten cases of puerperal fever (using the term in a comprehensive sense) are the only oncs of the kind out of hundreds of reported instances in which the perchloride has been used, all of which were cases of severe post partum hæmorrhage. But post partum hæmorrhage is generally allowed to be a powerful predisponent of septicæmia. Therefore, it seems to me that the wonder is, not that ten cases of fatal septicæmia occurred out of these hundreds of cases, but that only ten occurred.

Let us look at the matter a little more closely, and ask ourselves in what way the perchloride can be imagined to give rise to these untoward symptoms. Is it by some of the fluid passing through the Fallopian tubes into the peritoneum? In that case, severe pain and fatal shock would probably be the result, or, if not, acute peritonitis would quickly supervene; whereas, in all these cases of septicremia, we are told that the patient was doing well for three or four days, or even for a week, before unfavourable symptoms set in. Is it by causing coagulation of blood in -the uterine sinuses? This, if it spread to the iliac veins, might give rise to phlegmasia dolens, which has occasionally followed the injection, but which does not appear to have been a prominent symptom in the cases of septicæmia which we are considering. Is it by decomposition of clots in the uterine sinuses giving rise to blood-poisoning? We know that clots in veins are not, as a rule, liable to cause septicæmia. Then why should clots which have been produced by the action of so powerful a disinfectant as the perchloride of iron be especially liable to do so? On the contrary, Dr. Connel has shown by experiments that coagula produced by the action of the iron salt are peculiarly aseptic, and resist putrefactive change for an extraordinarily long time (Edinlutrgh Medical Fournal, vol. $\mathrm{xx}, \mathrm{p.} 852$ ).

There is one danger, no doubt, viz., that hard coagula within the womb may decompose and set up fever; but this is readily prevented by irrigating the uterus with disinfecting fluids. In illustration of this

* I have to-day (April 28th) received a letter from Dr. W. Clement Daniel of E.psom, in which he kindly gives me full particulars of Mr. Stilwell's case. Dr. Daniel himself attended the labour, but Mr. Stilwell was called in to assist, and subsequently read a paper on the case. The labour was tedious, and at the end of twenty-four hours the long forceps was applied. Hæmorrhage came on a short time after delivery, and the patient soon became collapsed. 'The uterus having been emptied of clots, solution of the perchloride was injected, which only partially arrested the bleeding. The injection was used three times, but each time it failed to permanently stop the hæmorrhage, of which the patient died two hours after delivery. She had been in a poor state of health for some time before the confinement, and death appeared to be caused solely by exhaustion. Dr. Daniel adds: "I have used the injection fifteen times in the last twelve years, and with this exception always effectually." 
point, I may refer to a very instructive case welated by .Dr. Playfair. The patient's life was saved in two successive labpurs by the use of the perchloride. In the second instance; foverish symptoms, appeared on the third day. The uterus was freely and frequently washed out with Condy's fluid; offensive clots came away at intervals for three days, after which the fever subsided and the patient did well (Obstetrical Journal, vol. i, p. 92). Dr. Braxton Hicks also refers to a similar case (Ibid., p. 45).

Finally, it can hardly be maintained that the perchloride causes inflammation of the substance of the uterus, which spreads through to the peritoneum: Such a supposition is negatived by the fact that the patients have almost invariably done very well for three or four days, or longer. Moreover, Dr. Atthill, in describing the post mortem appearances in one of his cases, where death followed a few. hours after the injection, says that "in no place was there the slightest discoloration of the uterine walls subjacent to the mucous membrane; nor any trace of iron in the uterine veins" (Dublin Journal of Medical Science, vol. lxiii, p. 584).

It is difficult to see how the perchlorido should cause puerperal fever if not in one of these four ways; and I think I have shown that there is no good reason for believing that it would or does do so, unless it be in the way suggested by Drs. Braxton Hicks and Playfair-viz., by decomposition of clots within the uterus; and this is, of course, an occurrence that can be readily prevented.

As regards the other cases in which septicæmia has supervened, it has come on at about the same time and with the same symptoms as puerperal fever commonly does; and I can see no good ground for believing that the injection of iron has had anything to do with its production.

To revert, then, to the questions with which this paper opened : What are the dangers of this operation, and how are they to be avoided?

I have endeavoured to show that puerperal fever is not one of the dangers to be apprehended from the use of the perchloride. But there are two accidents which apparently may be caused by the injection. One is the forcing of some of the fluid along the Fallopian tubes to the peritoneal cavity, causing severe pain and fatal shock, which probably (though not certainly) occurred in one reported case (Dr. Bantock's). The other is the entrance of the ferruginous solution into the uterine veins, causing phlegmasia dolens, or even giving rise to cardiac or pulmonary embolism and sudden death. This accident may have been the cause of death in three of the cases I have described; but there is no doubt that it can with almost complete certainty be avoided; firstly, by being most careful to keep open the cervix. with the fingers, so as to allow the free egress of the fluid injected; secondly, by injecting very slowly and gently, allowing the solution to trickle down the sides of the uterus, and by avoiding all unnecessary force. To attain this end; it is desirable to employ a delivery-tube, which, instead of having one large terminal aperture, has a number of small lateral ones, so as to send a coarse spray rather than a full stream against the interior of the uterus ; and attention to these precautions will probably reduce the risks of the operation to a minimum.

But even if these dangers were greater than they are, we should not, in my opinion, be justified in giving up the operation altogether. It has undoubtedly saved many lives which were fast ebbing away, when nothing else would stay the perilous flux. If we are to discard every operation which is itself sometimes fatal, what would become of ovariotomy, lithotomy, or amputation of the breast? A woman flooding to death is in far more immediate peril than are those for whom the operations just named are performed. Then why should she be denied a remedy, which has saved many women's lives, all other means having failed, because it may not be absolutely free from danger? For my own part, I believe that every practitinner ought to carry this, or some equally efficient styptic (if such there be), to every case of midwifery to which he is summoned. This conviction has been forced upon me by the perusal of some of those terrible cases where life has rapidly ebbed away before there was time to fetch any assistance, or any remedies beyond what the attendant had with him. Take such a case as this. Dr. Brisbane reports that he had used the perchloride in several cases with excellent effect; but, not having had a case of hæmorrhage for some time, he had given up carrying it with him as a matter of routine. $\mathrm{He}$ was called to a case in the night. Terrific hæmorrhage followed. He did all he could to arrest it, and sent for some perchloride, but before it could be fetched the patient was dead, within half an hour of the birth of the child. Dr. Brisbane says, with reason, that; if he had had the perchloride with him, it is almost certain that the patient's life would have been saved (Lancet, 1877 , vol. $\mathrm{ii}, \mathrm{p} .277$ ). Here is another case. Mr. T. F. Williams says : "Two years ago, I was just in time to save a young woman with the perchloride-a primipara-at whose birth her mother had flooded to death. When I was in London last spring, she was again taken in labour. The gentleman in charge of my practice was ptejudiced against the use of perchtoride of iton. Every routine remedy was used, but in four hours after the birth of the child the mother was a corpse" (Obstetrical Joumal, vol. i, p. 595).

Dr. Lombe Atthill narrates a case to the same effect. He says : "I have lost at least one patient of post partum hæmorrhage, whose bedside I never left from the termination of the first stage of labour till death ensued.........In her case, I exhausted all the ordinary methods employed for the arrest of hæmorrhage, but my patient died before my, eyes......... r regret to say, I did not inject the perchloride of iron" (Dublin Journal of Medical Science, vol. 1vii, p. 347). He goes on to explain that it was not long after Dr. Barnes had brought forward this method of treatment, and that he (Dr. Atthill) was afraid of it. This timidity he blames for the loss of his patient.

My own experience of the operation, though not extensive, has been altogether favourable. I have used it in cases where injections both of hot water and of vinegar have failed, and where to all appearance the patients would inevitably have died without the iron.

In conclusion, then, I believe that there are some cases of post parturm hæemorrhage of so intractable a character that the injection of a solution of the perchloride of iron into the uterus affords the only chance of saving the patient's life ; and for this reason I consider that, of all the numerous benefits which my respected teacher Dr. Barnes has conferred upon obstetric science and practice, not the least important is the introduction of the method of treatment whose alleged dangers I have in this paper endeavoured to estimate.

\section{THERAPEUTIC MEMORANDA.}

\section{COMBINATIONS OF GLYCERINE AND BORAX.}

WITH reference to Mr. Fred. Long's note in the Jou RNAL for April Ioth, respecting the joint action of borax, glycerine, and the sodic carbonates, I recollect having my attention drawn to a letter in one of the medical journals in the summer of 1873 from a practitioner, who detailed the untoward results of combining sodic carbonate with the glycerine of borax, and who asked for an explanation of the explosive action. No explanation was forthcoming at the time, but anyone who chooses to repeat the few experiments which I was induced to undertake, will find the following results.

I. If pure neutral glycerine be added to pure borax or to a solution of this salt in water, the mixture becomes distinctly acid to test-paper; and the presence of free boric acid is now revealed by appropriate tests (e.g., teste the glycerine of borax $B$. P.).

2. When the carbonate or bicarbonate of soda is added to such a mixture as the one last mentioned, a distinct effervescence takes place, the free boric acid ousting the carbon dioxide from the sodic carbonate, and combining with the base to form borax again, while the carbonic acid gas escapes in effervescence.

It is remarkable that, while glycerine-or rather glyceric acid-at once displaces boric acid from its sodium compound, its energy of combination with the metal is less even than that of the weak carbonic acid; for, as Mr. Long correctly states, no action occurs when glycerine only is added to the sodium carbonates. The behaviour of the glycerines and their compounds presents several points. of interest not yet thoroughly worked out; and in practice it is at least worth while to remember, first, that the so-called glycerine of borax is not a simple mixture of the two bodies named, but contains a glycerate of sodium and free boric acid; second, the consequences which may naturally be looked for if a weak carbonate be brought into chemical contact with such a mixture containing a more powerful free acid.

Chas. Edwd. Shelly, B.A., M.B. (Cantab.), Hertford.

\section{PANCREATIC GLYCERINE.}

By way of postscript to my paper in a recent number, I wish to modify two of my statements. At the time I wrote, I did not know that there was a glycerine of pancreatine in the market; but Mr. Benger has since sent me a sample-which is, I find, satisfactorily active, although made some time ago- of a "pancreatic glycerine", manufactured by the firm of Mottershead at Dr. Roberts's suggestion, and shown amongst the Materia Medica exhibits at the Association meeting at Manchester in 1876. Why it has been superseded in Dr. Roberts's estimation by the "liquor pancreaticus" I do not know, save that adults dislike its sweet taste. I intend to give it a trial in children's diseases.

Mr. Benger further says I described his liquor pancreaticus as "bitterish" in taste: if so, this was a lapsus calami, purely inadvertent. I did not write with Mr: Benger's two liquors-peptic and pancreaticbefore me, and I meant to say that the "liquor pepticus" sample sent to 